\title{
$2 \mathrm{kV}$ slanted tri-gate GaN-on-Si Schottky barrier diodes with ultra-low leakage current
}

Jun Ma, and Elison Matioli

Citation: Appl. Phys. Lett. 112, 052101 (2018); doi: 10.1063/1.5012866

View online: https://doi.org/10.1063/1.5012866

View Table of Contents: http://aip.scitation.org/toc/apl/112/5

Published by the American Institute of Physics

\section{Articles you may be interested in}

Guest Editorial: The dawn of gallium oxide microelectronics

Applied Physics Letters 112, 060401 (2018); 10.1063/1.5017845

Vertical leakage induced current degradation and relevant traps with large lattice relaxation in AIGaN/GaN heterostructures on $\mathrm{Si}$

Applied Physics Letters 112, 032104 (2018); 10.1063/1.5009525

Doping and compensation in Al-rich AIGaN grown on single crystal AIN and sapphire by MOCVD Applied Physics Letters 112, 062102 (2018); 10.1063/1.5011984

Structural and optical properties of semi-polar (11-22) InGaN/GaN green light-emitting diode structure Applied Physics Letters 112, 052105 (2018); 10.1063/1.4997319

Spatially dependent carrier dynamics in single InGaN/GaN core-shell microrod by time-resolved cathodoluminescence

Applied Physics Letters 112, 052106 (2018); 10.1063/1.5009728

Impact of crystal orientation on the modulation bandwidth of InGaN/GaN light-emitting diodes

Applied Physics Letters 112, 041104 (2018); 10.1063/1.5019730

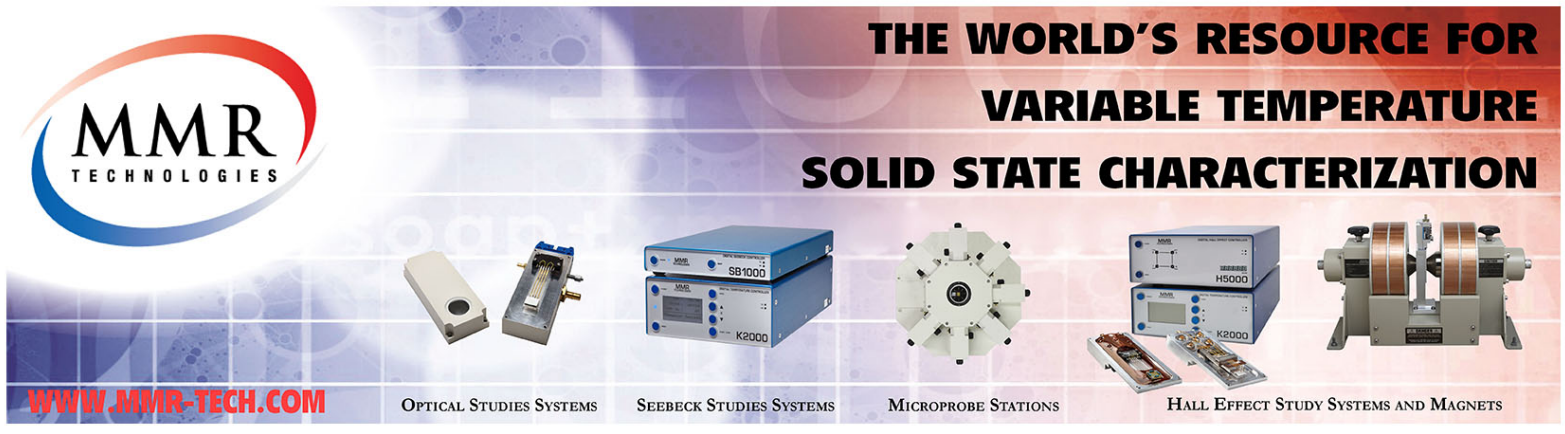




\title{
$2 \mathrm{kV}$ slanted tri-gate GaN-on-Si Schottky barrier diodes with ultra-low leakage current
}

\author{
Jun $\mathrm{Ma}^{\mathrm{a})}$ and Elison Matiolib) \\ Power and Wide-Band-Gap Electronics Research Laboratory, École polytechnique fédérale de Lausanne (EPFL), \\ CH-1015 Lausanne, Switzerland
}

(Received 8 November 2017; accepted 12 January 2018; published online 29 January 2018)

\begin{abstract}
This letter reports lateral GaN-on-Si power Schottky barrier diodes (SBDs) with unprecedented voltage-blocking performance by integrating 3-dimensionally a hybrid of tri-anode and slanted trigate architectures in their anode. The hybrid tri-anode pins the voltage drop at the Schottky junction $\left(V_{\mathrm{SCH}}\right)$, despite a large applied reverse bias, fixing the reverse leakage current $\left(I_{\mathrm{R}}\right)$ of the SBD. Such architecture led to an ultra-low $I_{\mathrm{R}}$ of $51 \pm 5.9 \mathrm{nA} / \mathrm{mm}$ at $-1000 \mathrm{~V}$, in addition to a small turnon voltage $\left(V_{\mathrm{ON}}\right)$ of $0.61 \pm 0.03 \mathrm{~V}$. The slanted tri-gate effectively distributes the electric field in OFF state, leading to a remarkably high breakdown voltage $\left(V_{\mathrm{BR}}\right)$ of $-2000 \mathrm{~V}$ at $1 \mu \mathrm{A} / \mathrm{mm}$, constituting a significant breakthrough from existing technologies. The approach pursued in this work reduces the $I_{\mathrm{R}}$ and increases the $V_{\mathrm{BR}}$ without sacrificing the $V_{\mathrm{ON}}$, which provides a technology for high-voltage SBDs, and unveils the unique advantage of tri-gates for advanced power applications. Published by AIP Publishing. https://doi.org/10.1063/1.5012866
\end{abstract}

High-voltage rectifiers are crucial in nearly every topology of power converters, and GaN-on-Si Schottky barrier diodes (SBDs) are highly promising for such applications due to their superior performance and competitive cost. ${ }^{1-8}$ Moreover, they are lateral devices and can be monolithically integrated with GaN-on-Si transistors and circuits, which is highly desirable for future compact and efficient power converters. ${ }^{9,10}$

Despite these advantages, a major obstacle for GaN-on$\mathrm{Si}$ SBDs is their limited voltage-blocking performance. Efficient power devices must present high $V_{\mathrm{BR}}$ and small $I_{\mathrm{R}}$, which are however very challenging in GaN SBDs. First, the $I_{\mathrm{R}}$ in GaN SBDs is typically large, being dominated by many non-ideal effects that are very difficult to eliminate, such as tunneling. ${ }^{11}$ Second, although a small Schottky barrier $\left(\Phi_{\mathrm{B}}\right)$ leads to a small $V_{\mathrm{ON}}$, it also increases the $I_{\mathrm{R}}$, and thus, there is a natural trade-off between good ON- and OFF-state performances. Finally, the lateral current conduction in GaN SBDs results in an inhomogeneous distribution of the electric field, which severely limits their $V_{\mathrm{BR}}{ }^{12,13}$ despite the resistivity of their buffer layers. Consequently, the poor voltage-blocking capability in GaN-on-Si SBDs is usually limited by the device architecture, rather than their buffer layers. As an example, the voltage-blocking performance of GaN-on-Si SBDs is still much inferior than that of GaN-onSi transistors, even though they share the same material platform. While GaN-on-Si power transistors have been commercialized for applications up to $650 \mathrm{~V}, \mathrm{GaN}-o n-\mathrm{Si}$ SBDs for such ratings are still missing.

In this work, we demonstrate that high-performance GaN-on-Si power SBDs with superior voltage-blocking capabilities $(2 \mathrm{kV}$ at $1 \mu \mathrm{A} / \mathrm{mm})$ can be achieved with a judicious device design, by integrating hybrid tri-anode (TA) and slanted tri-gate (TG) architectures. The hybrid tri-anode

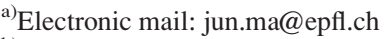

b)Electronic mail: elison.matioli@epfl.ch
}

reduced the $I_{\mathrm{R}}$ by controlling the $V_{\mathrm{SCH}}$ with the width of its nanostructures $(w)$, resulting in an ultra-low $I_{\mathrm{R}}$ of $51 \pm 5.9 \mathrm{nA} /$ $\mathrm{mm}$ at $-1000 \mathrm{~V}$ and in a small $V_{\mathrm{ON}}$ of $0.61 \pm 0.03 \mathrm{~V}$. The slanted tri-gate provided a continuous gradient of pinch-off voltage $\left(V_{\mathrm{p}}\right)$ from the anode towards the cathode, spreading effectively the electric field in OFF state, leading to a record $V_{\mathrm{BR}}$ of $2 \mathrm{kV}$ at $1 \mu \mathrm{A} / \mathrm{mm}$. These results establish a milestone for GaN power devices and could lead to enormous opportunities for future monolithic $\mathrm{GaN}$ power circuits.

The $\mathrm{Al}_{0.25} \mathrm{Ga}_{0.75} \mathrm{~N} / \mathrm{GaN}$ heterostructure in this work was grown on a silicon substrate with $5 \mu$ m-thick buffer layers. The fabrication of the slanted tri-gate SBDs (Fig. 1) started with e-beam lithography to define the nanostructures in the anode, which were etched by inductively coupled plasma with a depth of $\sim 180 \mathrm{~nm}$. The width $(w)$ and spacing of the nanostructures in the tri-gate and tri-anode regions were $200 \mathrm{~nm}$ and $400 \mathrm{~nm}$, respectively, while the $w$ in the slanted tri-gate region increased continuously from $200 \mathrm{~nm}$ to $600 \mathrm{~nm}$

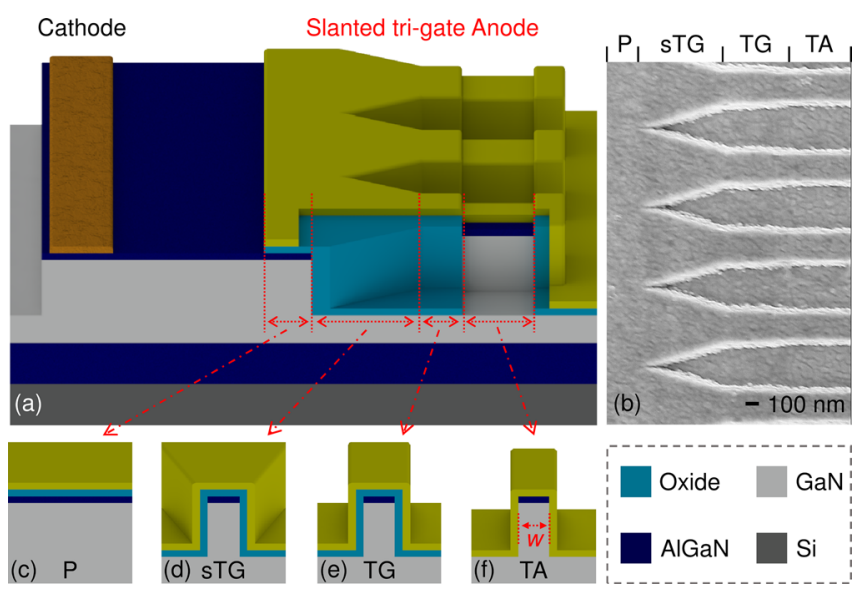

FIG. 1. (a) Schematic of the slanted tri-gate SBD and (b) a top-view scanning electron microscopy (SEM) image of the anode region. Cross-sectional schematics of the (c) planar (P), (d) slanted tri-gate (sTG), (e) tri-gate (TG), and (f) tri-anode (TA) regions comprising the anode. 
towards the cathode. The devices were isolated by mesa etching, and the cathode ohmic contact was formed by alloying $\mathrm{Ti} / \mathrm{Al} / \mathrm{Ti} / \mathrm{Ni} / \mathrm{Au}$ at $830^{\circ} \mathrm{C}$. Then, $10 \mathrm{~nm} \mathrm{SiO}{ }_{2}$ and $10 \mathrm{~nm} \mathrm{Al}{ }_{2} \mathrm{O}_{3}$ were deposited by atomic layer deposition and selectively removed in the tri-anode region. Finally, the anode contact was formed with $\mathrm{Ni} / \mathrm{Au}$. The oxide in the access and ohmic regions was removed by wet etching, which did not affect the $I_{\mathrm{R}}$ in this work. The length of the planar $\left(L_{\mathrm{FP}}\right)$, slanted tri-gate $\left(L_{\mathrm{sTG}}\right)$, tri-gate $\left(L_{\mathrm{TG}}\right)$, and tri-anode $\left(L_{\mathrm{TA}}\right)$ regions was $1.3 \mu \mathrm{m}$, $0.7 \mu \mathrm{m}, 0.5 \mu \mathrm{m}$, and $4 \mu \mathrm{m}$, respectively (Fig. 1). All current values in this work were normalized by the width of the device footprint $(60 \mu \mathrm{m})$.

The schematic and equivalent circuit of the nanostructured anode are shown in Figs. 2(a) and 2(b), respectively. It consists of a tri-anode SBD connected in series with a trigate, a slanted tri-gate, and a planar-gate transistor. The main idea is to design the distribution of potential along the device in OFF state, by engineering the profile of $V_{\mathrm{p}}$ with $w$ in a single fabrication step, to obtain small $I_{\mathrm{R}}$ and high $V_{\mathrm{BR}}$. More specifically, the purpose of each component can be briefly explained as follows:

1. The tri-anode (TA) was designed for small $V_{\mathrm{ON}}{ }^{8,14}$ and low $I_{\mathrm{R}}{ }^{15}$ In ON state, the metal contacts the 2DEG directly at the sidewalls and hence leads to a small $V_{\mathrm{ON}}$. In OFF state, when the voltage is below the $V_{\mathrm{p}}$ of the tri-

(a)

(b)

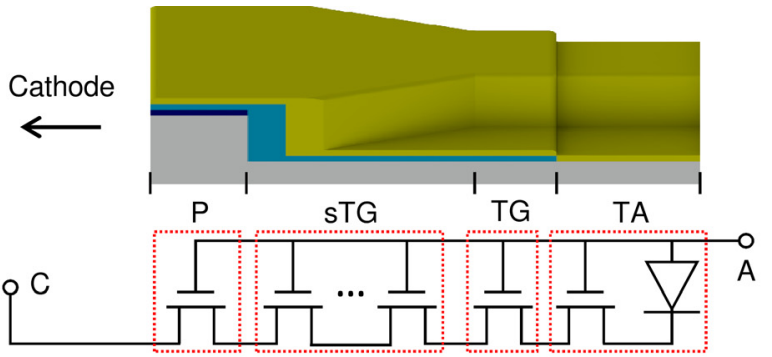

(c)
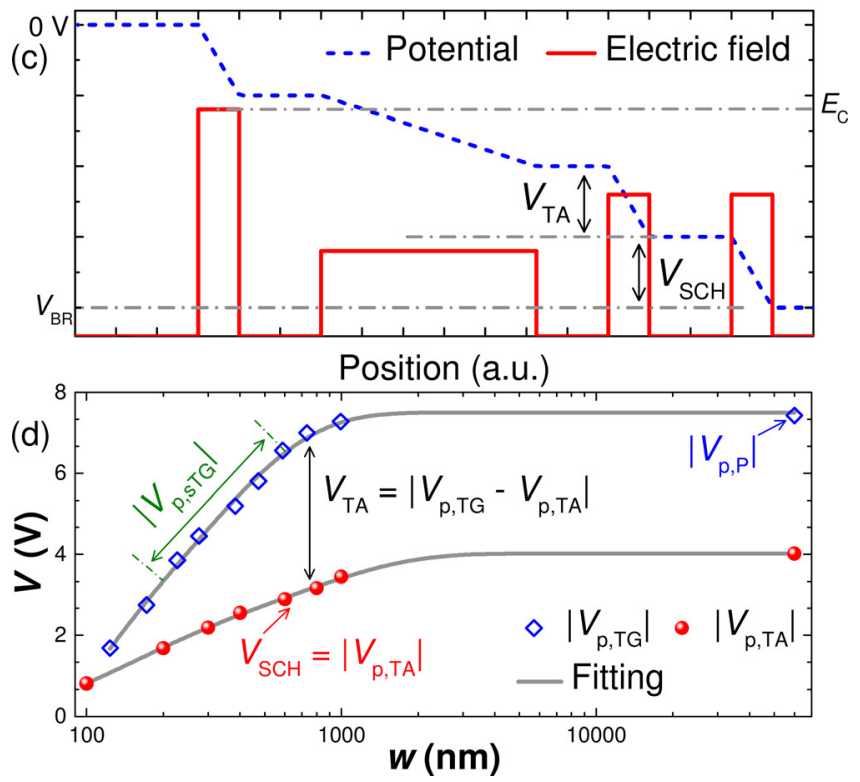

FIG. 2. (a) Schematic and (b) equivalent circuit of the slanted tri-gate SBDs. (c) Schematic showing the distribution of potential and electric field at the 2DEG channel in the SBD under a large reverse bias. (d) Averaged absolute value of the pinch-off voltage $\left(\left|V_{\mathrm{p}}\right|\right)$ as a function of the width (w) of the nanowires in tri-gated $\mathrm{AlGaN} / \mathrm{GaN}$ structures, determined from about eight devices of the each type fabricated on a control sample with $20 \mathrm{~nm} \mathrm{Al}_{2} \mathrm{O}_{3}$ as the oxide. anode $\left(V_{\mathrm{p}, \mathrm{TA}}\right)$, the $V_{\mathrm{SCH}}$ is pinned at $\left|V_{\mathrm{p}, \mathrm{TA}}\right|$ [Fig. 2(c)], which fixes the $I_{\mathrm{R}}$ at a constant level. $\left|V_{\mathrm{p}, \mathrm{TA}}\right|$ can be reduced continuously with smaller $w$ [Fig. 2(d)], resulting in a smaller $V_{\mathrm{SCH}}$ and hence in an exponentially lower $I_{\mathrm{R}}$, as quantified in our previous study. ${ }^{15}$ Therefore, here the $I_{\mathrm{R}}$ is controlled by $V_{\mathrm{SCH}}$, instead of by the $\Phi_{\mathrm{B}}$, so it can be reduced without sacrificing the $V_{\mathrm{ON}},{ }^{15}$ which decouples the $I_{\mathrm{R}}$ and $V_{\mathrm{ON}}$.

2. The tri-gate region (TG) was inserted to shield the trianode, since the TA is vulnerable to high electric fields, which are concentrated at its cathode-side edge, and can lead to large $I_{\mathrm{R}}$ and even early breakdown of the device. ${ }^{15}$ By connecting the TG in series with the TA, the voltage drop at the cathode-edge of the TA $\left(V_{\mathrm{TA}}\right)$ is pinned at $\left|V_{\mathrm{p}, \mathrm{TG}}-V_{\mathrm{p}, \mathrm{TA}}\right|$ [Fig. 2(c)], which can be also reduced with a smaller $w$ [Fig. 2(d)], when $w$ is below $1 \mu \mathrm{m}$, shielding the TA from large reverse biases. More details about the impact of the $w$ on device characteristics can be found elsewhere. ${ }^{1}$

3. The slanted tri-gate (sTG) was included to enhance the $V_{\mathrm{BR}} \cdot{ }^{16}$ It was patterned with a slanted $w$, increasing towards the cathode. Since the $\left|V_{\mathrm{p}}\right|$ in a tri-gate MOS structure reduces with smaller $w$ [Fig. 2(d)], the sTG works as many incrementally stepped field plates (FPs) ${ }^{16}$ with a continuous gradient of $\left|V_{\mathrm{p}, \mathrm{sTG}}\right|$ increasing towards the cathode. As a result, the electric field is spread along the entire sTG, which significantly improves the $V_{\mathrm{BR}}$ [Fig. 2(c)], similarly to conventional slanted FPs, but with the advantage of a much easier and more controllable fabrication by simply tuning the $w$ lithographically in a single step;

4. The long planar region $(\mathrm{P})$ works as a planar FP to further improve the $V_{\mathrm{BR}}$, since the $V_{\mathrm{p}}$ of the planar region $\left(V_{\mathrm{p}, \mathrm{P}}\right)$

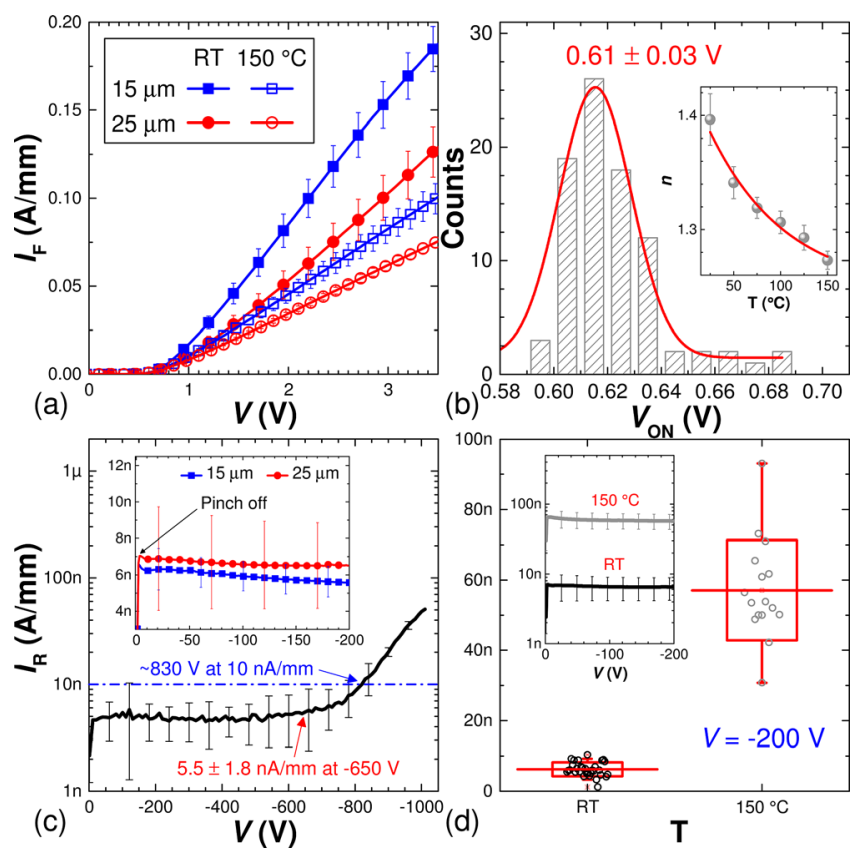

FIG. 3. (a) Forward $I-V$ characteristics and (b) distribution of $V_{\mathrm{ON}}$ of the slanted tri-gate SBDs. The inset shows the dependence of the estimated ideality factor $(n)$ upon the temperature $(T)$. (c) Average $I_{\mathrm{R}}$ from ten devices measured at room-temperature (RT) with a floating substrate connection. The value of $I_{\mathrm{R}}$ was independent from the substrate connection when $V$ was below $-900 \mathrm{~V}$. The inset shows the $I_{\mathrm{R}}$ with $15 \mu \mathrm{m}$ and $25 \mu \mathrm{m}$ of $L_{\mathrm{AC}}$ at RT. (d) $I_{\mathrm{R}}$ at $\mathrm{RT}$ and $150^{\circ} \mathrm{C}$ measured under a voltage of $-200 \mathrm{~V}$. The inset shows the reverse $I-V$ characteristics at different temperatures. 
is more negative with respect to the most negative value of the $V_{\mathrm{p}, \mathrm{sTG}} \cdot{ }^{16,17}$

The slanted tri-gate SBDs presented very good ON-state performance as shown in Fig. 3(a), despite the partial removal of the $2 \mathrm{DEG}$ in the anode. The ON-resistance $\left(R_{\mathrm{ON}}\right)$ was $13.9 \pm 1.3 \Omega \mathrm{mm}$ and $22 \pm 2.9 \Omega \mathrm{mm}$ at room temperature for devices with $L_{\mathrm{AC}}$ of $15 \mu \mathrm{m}$ and $25 \mu \mathrm{m}$, respectively, and increased to $27.6 \pm 2.9 \Omega \mathrm{mm}$ and $37 \pm 1.8 \Omega \mathrm{mm}$ at $150^{\circ} \mathrm{C}$. The $V_{\mathrm{ON}}$ was as small as $0.61 \pm 0.03 \mathrm{~V}$ [Fig. 3(b)], determined at $1 \mathrm{~mA} / \mathrm{mm}$. The ideality factor $(n)$ was $1.40 \pm 0.02$ at roomtemperature (RT) and reduced to $1.27 \pm 0.01$ at $150^{\circ} \mathrm{C}$ [inset in Fig. 3(b)], indicating the high quality of the sidewall Schottky contacts despite the etching.

In OFF state, the $I_{\mathrm{R}}$ of the slanted tri-gate SBDs was saturated after the pinch-off of the tri-anode at about $-1.7 \mathrm{~V}$ [the inset in Fig. 3(c)] due to the fixed $V_{\mathrm{SCH}}$, which was not affected by $L_{\mathrm{AC}}$, and thus, the $I_{\mathrm{R}}$ was nearly constant at $5.5 \pm 1.8 \mathrm{nA} /$ $\mathrm{mm}$ until $-650 \mathrm{~V}$ and did not reach $10 \mathrm{nA} / \mathrm{mm}$ until $-830 \mathrm{~V}$ [Fig. 3(c)]. Extremely low $I_{\mathrm{R}}$ of $51 \pm 5.9 \mathrm{nA} / \mathrm{mm}$ was observed at $-1000 \mathrm{~V}$, which is significantly smaller than in any other reports of GaN-on-Si SBDs. For voltages below $-900 \mathrm{~V}$, there was no significant difference in $I_{\mathrm{R}}$ measured with floating and grounded substrates. From RT to $150^{\circ} \mathrm{C}$, the $I_{\mathrm{R}}$ increased by only $\sim 50 \mathrm{nA} / \mathrm{mm}$ [inset of Fig. 3(d)], and at $150^{\circ} \mathrm{C}$, the $I_{\mathrm{R}}$ at $-200 \mathrm{~V}$ was as small as $57 \pm 13 \mathrm{nA} / \mathrm{mm}$ [Fig. 3(d)]. This is the smallest $I_{\mathrm{R}}$ among reported lateral GaN SBDs at such high temperature.

In addition to their small $V_{\mathrm{ON}}$ and ultra-low $I_{\mathrm{R}}$, the slanted tri-gate SBDs also presented high $V_{\mathrm{BR}}$ [Fig. 4(a)]. With floating substrate, the $V_{\mathrm{BR}}$ at $1 \mu \mathrm{A} / \mathrm{mm}$ was $-1450 \mathrm{~V}$ and $-2000 \mathrm{~V}$, and the hard breakdown was $-1500 \mathrm{~V}$ and $-2500 \mathrm{~V}$ for devices with $L_{\mathrm{AC}}$ of $15 \mu \mathrm{m}$ and $25 \mu \mathrm{m}$,

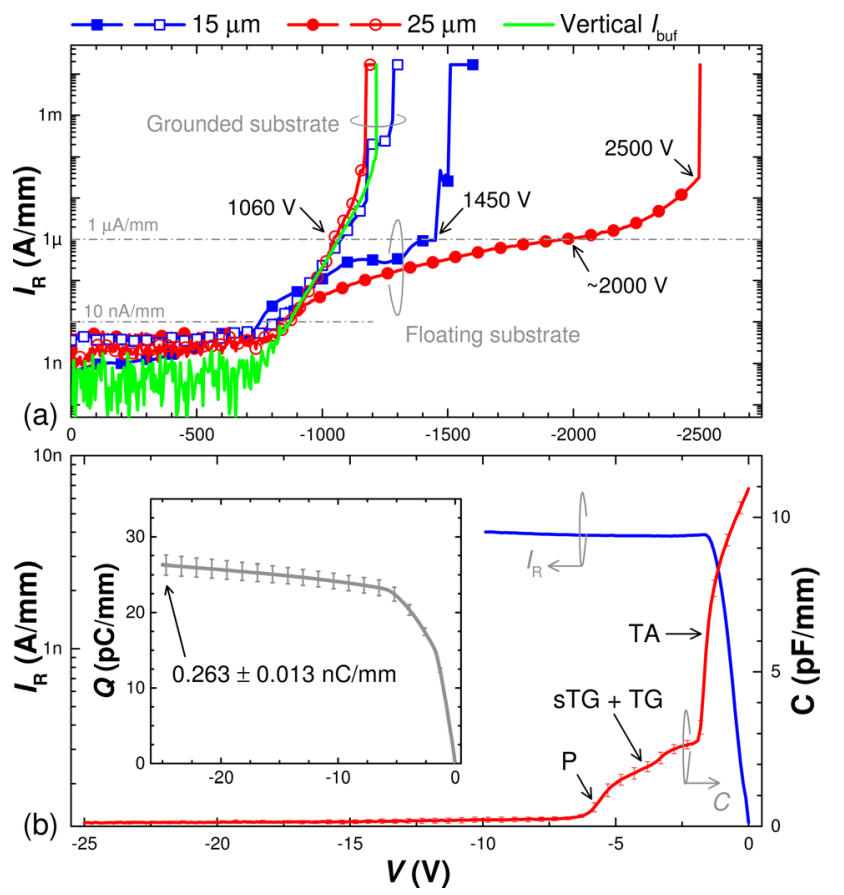

FIG. 4. (a) Breakdown characteristics of the slanted tri-gate SBDs, measured at room temperature. (b) The capacitance-voltage $(C-V)$ characteristics of the SBDs along with their $I_{\mathrm{R}}$. The inset shows the cumulative charge $\left(Q_{\mathrm{C}}\right)$ of the devices. The $C-V$ measurement was performed at $1 \mathrm{MHz}$ at room temperature, with negligible hysteresis observed from double-sweep measurements. respectively, corresponding to a critical breakdown field of $1 \mathrm{MV} / \mathrm{cm}$ (extracted from the hard breakdown voltage versus $L_{\mathrm{AC}}$ ). With grounded substrate, the $V_{\mathrm{BR}}$ at $1 \mu \mathrm{A} / \mathrm{mm}$ for both $L_{\mathrm{AC}}$ was about $-1060 \mathrm{~V}$, while the hard breakdown was up to $-1200 \mathrm{~V}$, which is comparable to current $650 \mathrm{~V}$-rated GaNon-Si power transistors ${ }^{18-21}$ and is limited by the vertical breakdown of the buffer layers. ${ }^{22}$ These results indicate that the $15 \mu \mathrm{m}-L_{\mathrm{AC}}$ SBDs can fulfill the voltage-blocking requirements of $600 / 650 \mathrm{~V}$ applications, even for those requiring grounded substrate connection, and the $25 \mu \mathrm{m}-L_{\mathrm{AC}}$ SBDs can be used for $1200 \mathrm{~V}$ applications (with floating substrate connection $^{22}$ ) both providing a safety margin in breakdown of about $100 \%$ (from the rated voltage to the hard breakdown).

Figure 4(b) shows the C-V measurement characteristics of the slanted tri-gate SBDs plotted along with the $I_{\mathrm{R}}$. The slanted tri-gate SBDs presented ultra-low $I_{R}$, because their $V_{\mathrm{SCH}}$ was pinned and the $I_{\mathrm{R}}$ saturated at the pinch-off of the tri-anode, at about $-1.7 \mathrm{~V}$ [Fig. 4(b)], instead of increasing exponentially with the voltage. This decouples the $I_{\mathrm{R}}$ from the $V_{\mathrm{ON}}$, allowing an independent design of the forward and reverse performance of the SBD, which is a major feature of this architecture. The high $V_{\mathrm{BR}}$ of the slanted tri-gate SBDs was due to the better-distributed electric field along the device. The continuity of the $C$ in the slanted tri-gate region [sTG + TG region in Fig. 4(b)] indicates a gradual depletion of the channel with increasing reverse bias, due to the gradient of $V_{\mathrm{p}}$, which spread effectively the electric field and greatly improved the $V_{\mathrm{BR}}$. Such an effect is similar to conventional slant $\mathrm{FPs}^{23}$ but obtained here with a more precise and controllable way of tuning the $w$ lithographically, instead of the complex sloped etch of the FP oxide.

The slanted tri-gate SBDs are also promising for fast switching, due to their small capacitive charge $\left(Q_{\mathrm{C}}\right)$ of $0.263 \pm 0.13 \mathrm{nC} / \mathrm{A}$ [inset of Fig. 4(b)], which is comparable to or below reported values for fast-switching $\mathrm{GaN}$ power SBDs on $\mathrm{Si}(0.415 \mathrm{nC} / \mathrm{A})^{24}$ and $\mathrm{SiC}(0.213 \mathrm{nC} / \mathrm{A})^{25}$ substrates. The switching time estimated from $Q_{\mathrm{C}}{ }^{2}$ was $\sim 263$ ps, which is about $25 \%$ shorter than that of conventional high-voltage GaN SBDs with double FPs. ${ }^{4}$

The high performance of the slanted tri-gate SBDs makes them excellent power rectifiers (Fig. 5), presenting

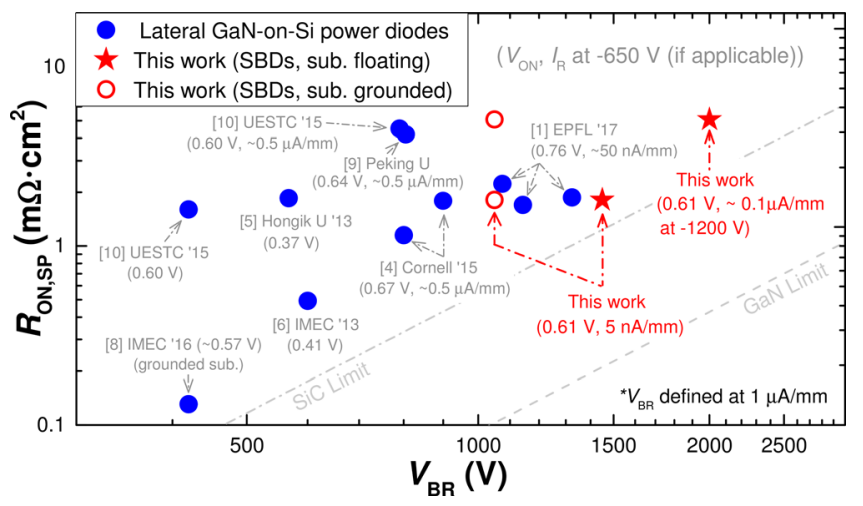

FIG. 5. Specific on-resistance $\left(R_{\mathrm{ON}, \mathrm{SP}}\right)$ versus $V_{\mathrm{BR}}$ benchmark of the slanted tri-gate SBDs against state-of-the-art lateral GaN-on-Si SBDs by defining the $V_{\mathrm{BR}}$ at $I_{\mathrm{R}}=1 \mu \mathrm{A} / \mathrm{mm}$. The $V_{\mathrm{BR}}$ for all reference devices was recalculated based on the reported data following the definition of $V_{\mathrm{BR}}$ at $I_{\mathrm{R}}=1 \mu \mathrm{A} / \mathrm{mm}$. For fair comparison, devices with unspecified $R_{\mathrm{ON}}$ or $I_{\mathrm{R}}$ were not included. 
the highest $V_{\mathrm{BR}}$, the lowest $I_{\mathrm{R}}$ of $5.5 \pm 1.8 \mathrm{nA} / \mathrm{mm}$ at $-650 \mathrm{~V}$ (or $\sim 0.1 \mu \mathrm{A}$ at $-1200 \mathrm{~V}$ ), a small $V_{\mathrm{ON}}$ of $0.61 \pm 0.03 \mathrm{~V}$, and an excellent high-power figure-or-merit up to $1.16 \mathrm{GW} / \mathrm{cm}^{2}$, as compared with existing GaN-on-Si power diodes with conventional technologies, rendering a breakthrough for the family of GaN-on-Si power devices.

In conclusion, in this letter, we presented $2 \mathrm{kV}$ GaN-on$\mathrm{Si}$ power SBDs by 3-dimensional integration of slanted tri-gate and hybrid tri-anode architectures. The hybrid trianode allows an independent design of the forward and reverse performances of the SBD, resulting in an ultra-low $I_{\mathrm{R}}$ and a small $V_{\mathrm{ON}}$. Together with the slanted tri-gate, a high $V_{\mathrm{BR}}$ of $-2000 \mathrm{~V}$ at $1 \mu \mathrm{A} / \mathrm{mm}$ was achieved, yielding a significant breakthrough from existing technologies. The approach presented in this work demonstrates a pathway to achieve high-voltage power SBDs and opens enormous opportunities for future monolithic GaN power converters.

This work was supported in part by the European Research Council under the European Union's H2020 program/ERC Grant Agreement No. 679425 and in part by the Swiss National Science Foundation under Assistant Professor Energy Grant No. PYAPP2_166901.

${ }^{1}$ J. Ma and E. Matioli, IEEE Electron Device Lett. 38, 83 (2017).

${ }^{2}$ M. Zhu, B. Song, M. Qi, Z. Hu, K. Nomoto, X. Yan, Y. Cao, W. Johnson, E. Kohn, D. Jena, and H. G. Xing, IEEE Electron Device Lett. 36, 375 (2015).

${ }^{3}$ J.-G. Lee, B.-R. Park, C.-H. Cho, K.-S. Seo, and H.-Y. Cha, IEEE Electron Device Lett. 34, 214 (2013).

${ }^{4}$ S. Lenci, B. D. Jaeger, L. Carbonell, J. Hu, G. Mannaert, D. Wellekens, S. You, B. Bakeroot, and S. Decoutere, IEEE Electron Device Lett. 34, 1035 (2013).

${ }^{5}$ J. Hu, S. Stoffels, S. Lenci, B. Bakeroot, B. D. Jaeger, M. V. Hove, N. Ronchi, R. Venegas, H. Liang, M. Zhao, G. Groeseneken, and S. Decoutere, IEEE Trans. Electron Devices 63, 997 (2016).

${ }^{6}$ J. Gao, M. Wang, R. Yin, S. Liu, C. P. Wen, J. Wang, W. Wu, Y. Hao, Y. Jin, and B. Shen, IEEE Electron Device Lett. 38, 1425 (2017).
${ }^{7}$ Q. Zhou, Y. Jin, Y. Shi, J. Mou, X. Bao, B. Chen, and B. Zhang, IEEE Electron Device Lett. 36, 660 (2015).

${ }^{8}$ E. Matioli, B. Lu, and T. Palacios, IEEE Trans. Electron Devices 60, 3365 (2013).

${ }^{9}$ W. Chen, K. Y. Wong, and K. J. Chen, IEEE Electron Device Lett. 30, 430 (2009).

${ }^{10}$ R. Reiner, P. Waltereit, B. Weiss, M. Wespel, M. Wespel, M. Mikulla, R. Quay, and O. Ambacher, in International Exhibition and Conference for Power Electronics (2016), p. 1.

${ }^{11}$ D. Yan, H. Lu, D. Cao, D. Chen, R. Zhang, and Y. Zheng, Appl. Phys. Lett. 97, 153503 (2010).

${ }^{12}$ R. Coffie, IEEE Trans. Electron Devices 61, 2867 (2014).

${ }^{13}$ S. Karmalkar and U. K. Mishra, IEEE Trans. Electron Devices 48, 1515 (2001).

${ }^{14}$ J. Ma, G. Santoruvo, P. Tandon, and E. Matioli, IEEE Trans. Electron Devices 63, 3614 (2016).

${ }^{15}$ J. Ma, D. C. Zanuz, and E. Matioli, IEEE Electron Device Lett. 38, 1298 (2017).

${ }^{16}$ J. Ma and E. Matioli, IEEE Electron Device Lett. 38, 1305 (2017).

${ }^{17}$ J. Ma and E. Matioli, IEEE Electron Device Lett. 38, 367 (2017).

${ }^{18}$ P. Moens, C. Liu, A. Banerjee, P. Vanmeerbeek, P. Coppens, H. Ziad, A. Constant, Z. Li, H. De Valeeschouwer, J. Roig-Guitart, P. Gassot, F. Bauwens, E. Debacker, B. Padmanabhan, A. Salih, J. Parsey, and M. Tack, in IEEE International Symposium on Power Semiconductor Devices \& IC's (2014), p. 374.

${ }^{19}$ T. Nagahisa, H. Ichijoh, T. Suzuki, A. Yudin, A. O. Adan, and M. Kudo, Jpn. J. Appl. Phys., Part 1 55, 04EG01 (2016).

${ }^{20}$ S. Kaneko, M. Kuroda, M. Yanagihara, A. Ikoshi, H. Okita, T. Morita, K. Tanaka, M. Hikita, Y. Uemoto, S. Takahashi, and T. Ueda, in IEEE International Symposium on Power Semiconductor Devices \& IC's (2015), p. 41.

${ }^{21}$ D. W. Seo, H. G. Choi, J. Twynam, K. M. Kim, J. S. Yim, S.-W. Moon, S. Jung, J. Lee, and S. D. Roh, IEEE Electron Device Lett. 35, 446 (2014).

${ }^{22}$ G. Tang, J. Wei, Z. Zhang, X. Tang, M. Hua, H. Wang, and K. J. Chen, IEEE Electron Device Lett. 38, 937 (2017).

${ }^{23}$ J. Wong, K. Shinohara, A. L. Corrion, D. F. Brown, Z. Carlos, A. Williams, Y. Tang, J. F. Robinson, I. Khalaf, H. Fung, A. Schmitz, T. Oh, S. Kim, S. Chen, S. Burnham, A. Margomenos, and M. Micovic, IEEE Electron Device Lett. 38, 95 (2017).

${ }^{24}$ E. Bahat-Treidel, O. Hilt, A. Wentzel, J. Würfl, and G. Tränkle, Phys. Status Solidi C 10, 849 (2013).

${ }^{25}$ E. Bahat-Treidel, O. Hilt, R. Zhytnyska, A. Wentzel, C. Meliani, J. Würfl, and G. Tränkle, IEEE Electron Device Lett. 33, 357 (2012). 